\title{
Cystic nephroma treated with nephron-sparing technique: A case report
}

\author{
RAFFAELE BAIO $^{1}$, NICOLA SPIEZIA ${ }^{2}$ and MANLIO SCHETTINI $^{2}$ \\ ${ }^{1}$ Department of Urology, University of Salerno, I-84081 Salerno; ${ }^{2}$ Department \\ of Urology, Lourdes Clinic, I-80040 Massa di Somma, Italy
}

Received August 21, 2020; Accepted March 1, 2021

DOI: $10.3892 / \mathrm{mco} .2021 .2271$

\begin{abstract}
Multilocular cystic nephroma is a rare benign kidney tumor, which is typically characterized by a unilateral, multicystic renal mass without solid elements. Cystic nephroma has a bimodal distribution and two-thirds of tumors involve children aged between 3 months and 2 years, with male predominance; a second peak affects the age group $>30$ years old, in which females are predominantly affected. The incidence rate for this rare tumor in patients aged 5-30 years is only 5\%. The present study reports a case of a 31-year-old woman affected by a multilocular cystic nephroma in the upper pole of the right kidney, with direct tumor extension into the renal pelvis through a calyx. After a partial nephrectomy on the patient, the pathological examination confirmed a multilocular cystic nephroma in the right renal specimens.
\end{abstract}

\section{Introduction}

Multilocular Cystic Nephroma (MCN) is an uncommon clinical entity; it looks like a well-circumscribed encapsulated mass with numerous locules and septa. The etiology of MCN is unclear and its histogenesis is arguable. This tumor type has been nicknamed in the past as multilocular cystic tumor, renal multilocular cyst, multilocular cystic nephroma, renal cystadenoma and partial polycystic kidney $(1,2)$ and it has been considered as a developmental lesion with malignancy potential. Approximately 200 cases have been described in the literature (3). The first of these was reported in 1892 by Edmunds (4): He removed a Cystic Nephroma of the kidney from an 18-year-old female. Recent advances in diagnostic imaging have resulted in an increased awareness of this type of renal tumor, and surgical intervention is an operative method for treating malignant cystic lesions of the kidney. However,

Correspondence to: Dr Raffaele Baio, Department of Urology, University of Salerno, Via Pareti 224, Nocera Superiore, I-84015 Salerno, Italy

E-mail: raffy.baio@yahoo.it

Key words: cystic nephroma, nephron sparing technique, Bosniak classification nephron-sparing surgery may be an option depending on the site and size of the lesion.

The present study reports a case of a 31-year-old woman, who was determined to have a Cystic Nephroma while the underlying cause of a protracted intermittent right renal painful condition was investigated.

\section{Case report}

A 31-year-old woman was admitted to the Division of Urology with a history of intermittent right-flank pain. She disclaimed other eliminating complaints and did not exhibit other significant urological diseases. The physical examination did not reveal any other significant symptoms except for a mild knocking pain in the right kidney area. Laboratory examinations revealed only the presence of microscopic hematuria, and so the urinalysis showed a mild quantity of red blood cells in the sediment. Urine cytology was negative for malignancy. To investigate potential causes of this intermittent right-flank pain the patient underwent abdominal ultrasound (US) imaging that showed a well-demarcated, complex cystic growth, with a maximum diameter of $\sim 3 \mathrm{~cm}$ in the upper pole of the right kidney. Ascending pyelography imaging revealed a large defect in the right renal pelvis. Computed tomography (CT) confirmed the presence of this growth, which originated from the renal parenchyma and extended into the right renal pelvis, as shown in Fig. 1.

In addition, the computed tomography revealed the presence of calcifications in the cyst without solid components. An enhanced CT scan showed a cystic lesion. In this case the obstruction by pelvic herniation of the tumor produced delayed excretion with hydrocalycosis or no visualization. Distinguishing a malignant mass from a benign lesion was not possible with the imaging techniques. Consequently, in order to remove the tumor, according to the clinical and radiological findings, the nephron-sparing surgery was performed. By an open right flank approach the kidney was isolated with its vascular pedicle. The vascular pedicle was scheletonized and the renal artery was clamped; opening the upper pole of the kidney, a translucent, regular mass was noted in the upper calyx as presented in Fig. 2. The mass was completely isolated and its little pedicle was ligated: The mass was completely removed, saving the rest of the kidney. Then, the renal parenchima was sutured with continuous vicryl 000 suture. 


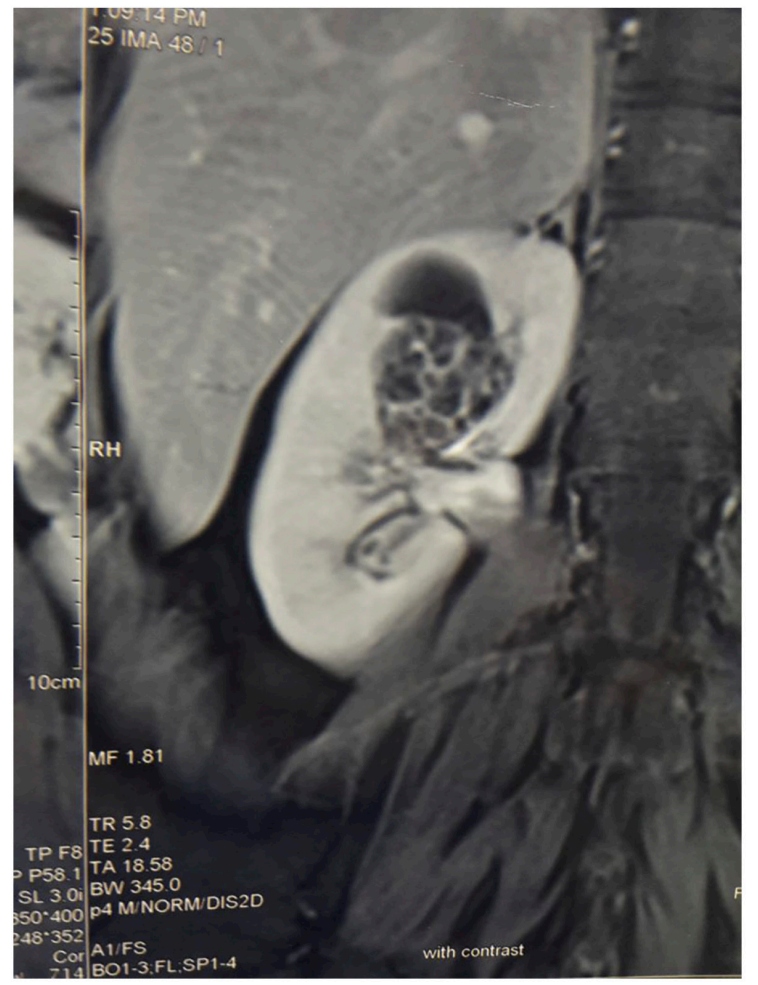

Figure 1. Computed tomography image showing the growth extending from the renal parenchyma.

The entire procedure was performed in $20 \mathrm{~min}$; then the artery was declamped and the bleeding was controlled. No lymphadenopathy or metastatic disease was present. Upper pole partial nephrectomy included the whole mass, with an area of normal appearing renal tissue. The mass originated in the renal parenchyma; however, it extended into the renal pelvis on a pedicle and the tumor bulk was entirely located within the renal pelvis. No malignancy was highlighted on a frozen section. The lesion was completely removed as presented in Fig. 3 and the rest of the kidney was saved.

The final histopathological diagnosis was Cystic Nephroma as shown in Figs. 4, 5 and 6 where large cystic formations with clear serous content are visible in a moderately vascularized fibrous stroma. Their lining epithelium is of a single-layered cubic type, without atypia and mitotic figures. The result, therefore, is a cystic formation, with a serous content, pure-chambered, with septa of varying thickness, whose external surface appears smooth and free of lesions.

The patient was discharged at 5 days post-operation. The vascular, ureteral, renal pelvis and capsular surgical margins were not affected by the tumor. After a 4-year follow-up, the patient was completely asymptomatic, without recurrence and metastasis.

\section{Discussion}

Cystic Nephroma is a rare benign lesion of the kidney and approximately 200 cases have been described in the literature. For the first time, this lesion was described in 1892 by Edmunds as 'cystadenoma of the kidney' (4). In most cases the lesion is asymptomatic and discovered incidentally during a radiological investigation performed for other reasons or

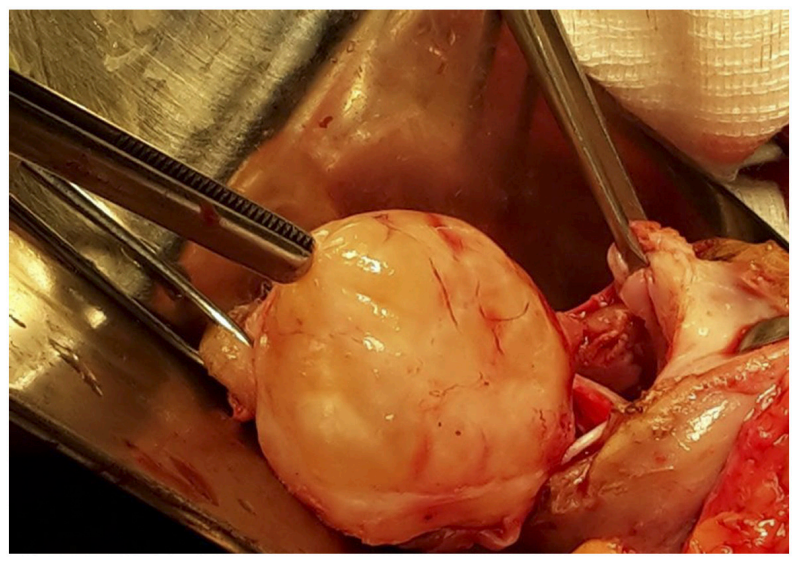

Figure 2. Result of the nephron-sparing procedure.

sometimes when the patient presents with non-specific urinary tract symptoms in adulthood or with an abdominal growth in childhood (5). Several proposed theories explain the etiology of Cystic Nephroma, considering it as a developmental defect (6). Others postulated that it could have neoplastic origin, likely arising from the ureteral bud. Therefore, the etiology of Cystic Nephroma has always been controversial (7), with the debate centering on whether this lesion is neoplastic or developmental in origin. Those who argue for a developmental origin suggest that Cystic Nephroma is a form of renal dysplasia, probably related to polycystic kidney disease, or a result of maldevelopment of the ureteric bud. According to others Cystic Nephroma arises from misplaced Mullerian stroma or it is a hamartomatous malformation. Many currently, like us, believe that Cystic Nephroma is a neoplasm. In the field of renal neoplasm, the term Cystic Nephroma has historically been problematic (8). As first deduced and asserted by John Eble in 1994 (9), the term 'Cystic Nephroma' has been used to refer to two apparently distinct lesions (7). The first, adult Cystic Nephroma, typically affects adult females (suggesting an association with circulating hormones) and has been thought by many to be the highly cystic end of the spectrum of Mixed Epithelial Stromal Tumor (MEST) (10). In contrast, pediatric Cystic Nephroma typically affects very young children (usually below 24 months of age) and has traditionally been thought to be part of the spectrum of cystic nephroblastic lesions that includes cystic partially differentiated nephroblastoma and cystic Wilms tumor. In the 2004 World Health Organization (WHO) classification of renal neoplasm, pediatric Cystic Nephroma is not recognized as a distinctive entity (11), instead considering adult Cystic Nephroma as a separate entity classified under soft tissue tumors of the kidney (12). Pediatric Cystic Nephroma is now considered a distinctive entity, associated with mutations in the DICER1 gene (13). Germline DICER1 mutations have been identified in young patients with pleuropulmonary blastoma and its other associated neoplasms, including pediatric Cystic Nephroma; this constellation of lesions is now termed DICER1 syndrome (14). Whether adult Cystic Nephroma should be grouped with MEST remains controversial. Some authors believe that these are distinctive entities, based upon the ability to separate lesions into one of these two categories in most cases (MEST being more solid and complex than Cystic Nephroma), with different morphology, immunoprofile 


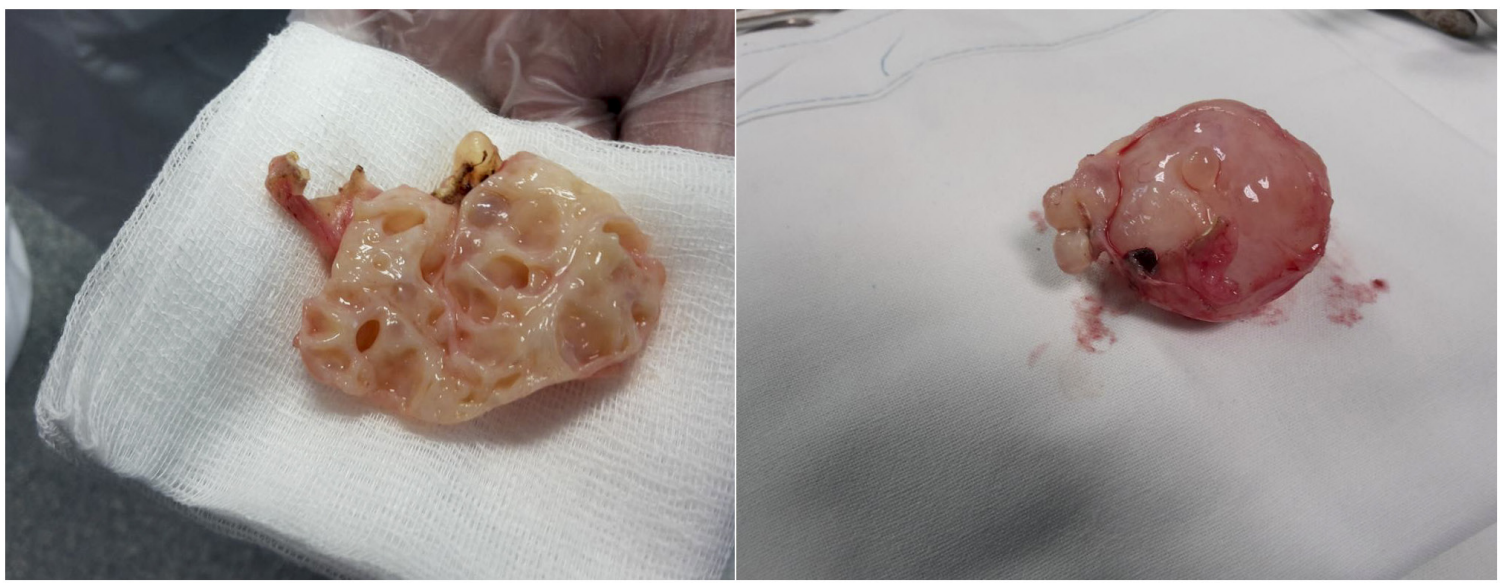

Figure 3. Final diagnosis of adult cystic nephroma. The figures show the anterior and posterior sides of the cystic lesion.

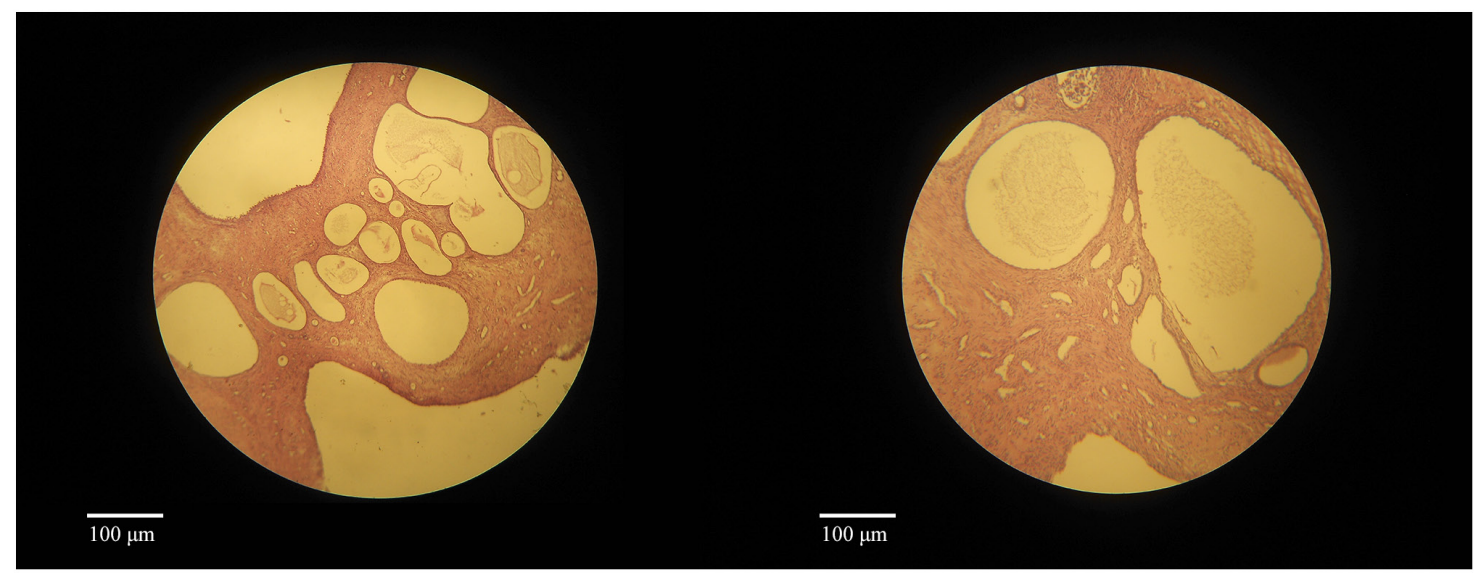

Figure 4. Histological sections, showing cysts of various sizes, covered by epithelium that is cylindrical in some parts and cubic-flat in others, without atypical characters. Scale bar, $100 \mu \mathrm{m}$.

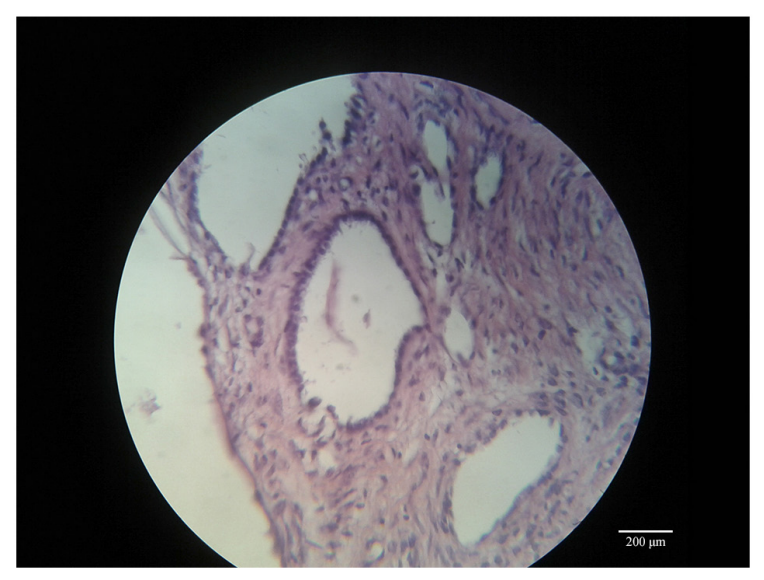

Figure 5. Highly magnified histological section showing the regularity of the lining epithelium, without atypia or karyokinetic figures. Scale bar, $200 \mu \mathrm{m}$.

(frequent smooth muscle differentiation in MEST and inhibin labeling in Cystic Nephroma) (15) and etiology (according to some MEST may not have appeared until after 1950 and may be linked to exposure to exogenous hormones such as oral contraceptives) (16). The current 2016 WHO Classification states that 'on the basis of similar age and sex distributions, as well as similar immunohistochemical profile and overlapping histologic features, adult Cystic Nephroma is now classified within the spectrum of MEST family' (17). Moreover, although the vast majority of adult Cystic Nephroma/MEST lack DICER1 mutations, rare cases currently classified as adult MEST may have DICER1 alterations, which likely are sporadic. Such lesions probably originated as Cystic Nephroma in childhood, but remained undetected until adult life and perhaps underwent morphologic changes (such as smooth muscle metaplasia) in the intervening years. Hence, DICER1 mutation status does not absolutely distinguish adult and pediatric Cystic Nephroma in all cases. In fact, also considering that ropy collagen and inhibin immunoreactivity are far more common in adult Cystic Nephroma/MEST than in pediatric lesion (being cellular stroma and estrogen receptor immunoreactivity commonly present in both cases), we argue that the marked differences in age, sex predominance, morphology and immunohistochemical profile support the current WHO Classification's separation of adult and pediatric cystic nephromas as distinct entities. The patient in the current study was a 31-year-old female, affected by intermittent right-flank pain and presenting with microscopic hematuria.

In 1956 Boggs and Kimmelstiel proposed these diagnostic criteria for a multilocular cyst (18): i) a multilocular growth; 


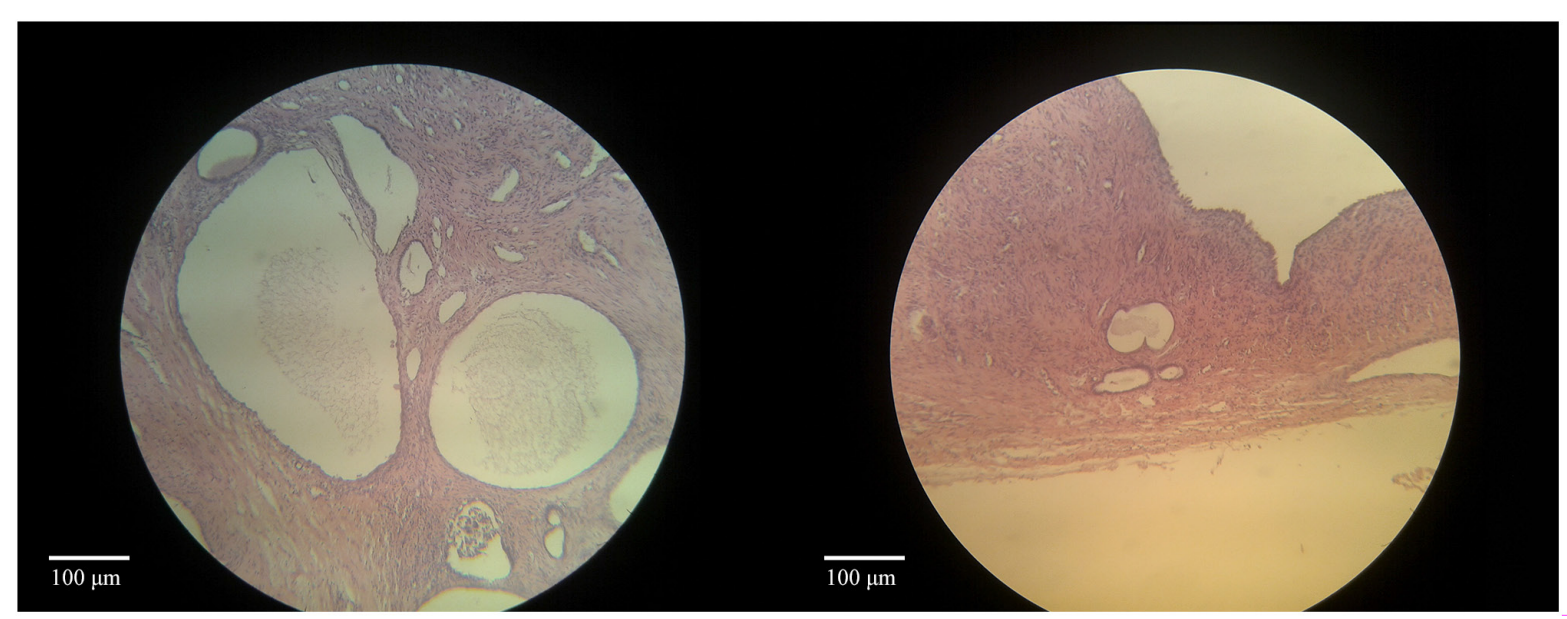

Figure 6. Histological sections showing a loose fibrous stroma surrounding the cystic formations, with a conspicuous vascular component. Notably, a small cyst with papillary aspects is visible in the left panel. Scale bar, $100 \mu \mathrm{m}$.

ii) the absence of communication not only between cysts but also between cysts and pelvis; iii) cysts lined by epithelium; iv) residual kidney essentially normal; and v) the absence of normal nephrons in the septa of cysts. In 1989 Joshi and Beckwith modified these criteria, specifying that: i) the lesion is composed entirely of cysts and their septa; ii) Cystic Nephroma is a lesion with separate and well-demarcated growth; iii) septa are the only solid components which conform to the outlines of the cyst without expansive nodules; iv) cysts are lined by flattened, cuboidal or hobnail epithelium; and v) septa contain fibrous tissue in which well-differentiated tubules may be present (19). The differential diagnosis of a cystic renal growth varies from adults to children, including several lesions such as polycystic kidney, nephroblastomas, Wilms' tumour, hydronephrotic kidney, mesoblastic nephroma and cystic renal cell carcinoma. Furthermore, due to the presence of Echinococcus granulosus in some countries, the Cystic Nephroma must be distinguished from the hydatid cyst (for which the treatment is medical). In some studies, the authors highlighted the coexistence of renal cell carcinoma or focal renal cell carcinoma with the Cystic Nephroma (20,21). The reason for this coexistence may be the potential malignant transformation of cystic epithelium or keratin positive stromal cells. Osathanondh and Potter, considering the lesion as a cyst, included Cystic Nephroma under 'type 2 polycystic kidneys' (22). However, we consider that Cystic Nephroma is a neoplasm; in effect, some studies showed that the tumor cells have multipotentiality in cellular differentiations and others reported the possibility of malignant transformation such as Raj et al who described a malignant Cystic Nephroma in an asymptomatic man (23). In addition, according to the Bosniak classification, for a type III cystic lesion (such as Cystic Nephroma) the probability of a malignant transformation is $\sim 55 \%$, justification for a resection of the cystic mass itself (24). For these reasons, the total excision of cystic nephroma is to be recommended. On the other hand, reliably distinguishing the Cystic Nephroma from a malignant lesion of the kidney by preoperative imaging or gross examination is very difficult. In effect, although the literature reports distinct radiographic features, these are not universally present in all cases. Imaging studies, such as US and CT, usually show the multilocular nature of the Cystic
Nephroma; however, the differential diagnosis between a class II and III cyst, based on the Bosniak classification, can be problematic. Therefore, surgical intervention is necessary for both diagnosis and treatment. According to the literature, nephrectomy is an adequate treatment and it does not need any chemotherapy and radiotherapy $(25,26)$. In addition, the nephron-sparing technique can be an adapted choice to treat the lesion (27). In fact, our inability to classify the renal mass as benign using common pre-operative imaging techniques has led us to adopt the same therapeutic strategy as for renal cell carcinoma. To date, partial nephrectomy, when surgically possible, is the first treatment option for T1 tumors. In effect, the EAU guidelines strongly recommend that consideration be given to performing a partial nephrectomy in patients with T1 cancer (28). According to the current Tumor Node Metastasis (TNM) staging system, stage T1 is defined as a tumor limited to the kidney, with dimensions equal to or $<7 \mathrm{~cm}$ (29). The renal mass reported in our clinical case, by virtue of its size, was classified as a stage T1a, justifying the choice of a conservative intervention. In addition, it should be noted that the nephron-sparing surgery for a type III Bosniak cyst was also warranted in view of the young age of the patient, the result of the extemporaneous histological examination during the operation and the associated symptoms (hematuria but also recurrent episodes of renal colic), which would hardly regress without surgery. Rather, due to the tendency of the cystic mass to increase in size with the passage of time, an exacerbation of the symptoms itself would certainly have occurred. In addition, regarding the comparison between surgery and preoperative histological correlation using renal biopsy in the case of an indeterminate cystic mass (such as Cystic Nephroma), some authors recommend biopsy. However, in the case of biopsy, the possibility of false negatives due to the small number of malignant cells in the cystic mass, the risk of seeding along the needle path and the risk of rupture of the cyst with spread of malignant cells must be considered. Therefore, the renal biopsy should only be performed when there are clinical grounds for suspecting that the mass is inflammatory (in case of pyuria, not present in our case) or when there are radiological signs suggestive of inflammation (hyperdensity of the perirenal adipose tissue, a sign not present in the images 
CT scan of the patient). To support this approach, the EAU guidelines offer only a weak recommendation to perform a preoperative kidney biopsy in patients with unclear kidney lesions (28). Therefore, although published reports consider nephrectomy as the classical surgical technique to treat the MCN (30,31), we suggest that nephron-sparing surgery, when surgically possible, may be the best choice of treatment when the diagnosis of Cystic Nephroma is suspected preoperatively and verified intraoperatively. A definitive diagnosis can typically be made from the result of the pathological examination when the operation is over. If the removed lesion is of benign nature, only surveillance is necessary after surgery.

In conclusion, considering the young age of the patient, the case described above has been singular for the choice of partial nephrectomy as a treatment modality. In addition, the study case presented another unique characteristic: The direct tumor extension into the renal pelvis through a calyx. This growth pattern may be a singular feature of MCN. In this case, the lesion was localized within the renal parenchyma but, as described in only two other cases $(32,33)$, herniation into the renal pelvis had occurred. Although rare, Cystic Nephroma must be kept in mind in the differential diagnosis of a renal mass. Because the age of presentation ranges from infancy to adulthood, both pediatric and adult surgeons may be called on to diagnose and treat Cystic Nephroma. In summary, the present study reports a case of a MCN with an unusual localization and for which the combination of clinical and radiological findings may help in lesion characterization, but only histology can provide the definitive diagnosis. We advocate the use of nephron-sparing technique as the most appropriate surgical treatment method for MCN when the diagnosis is suspected pre-operatively and verified intra-operatively on frozen section analysis; in the present case, performing a conservative surgical treatment, the kidney function was kept intact (a fundamental consideration when patients have a long life expectancy).

\section{Acknowledgements}

Not applicable.

\section{Funding}

No funding was received.

\section{Availability of data and materials}

All data generated or analyzed during this study are included in this published article.

\section{Authors' contributions}

MS and NS analyzed and interpreted the patient data regarding the urological disease. RB was a major contributor in writing the manuscript. All authors read and approved the final manuscript.

\section{Ethics approval and consent to participate}

Not applicable.

\section{Patient consent for publication}

Signed informed consent was obtained from the patient for publication of this case report and any accompanying images.

\section{Competing interests}

The authors declare that they have no competing interests.

\section{References}

1. Kuzgunbay B, Turunc T, Bolat F and Kilinc F: Adult cystic nephroma: A case report and a review of the literature. Urol Oncol 27: 407-409, 2009.

2. Falidas E, Ntasi A, Mathioulakis S, Vlachos K, Anyfantakis G, Boutzouvis S and Villias C: Multicystic nephroma in an elderly man. Case report. G Chir 32: 483-486, 2011.

3. Wilkinson C, Palit V, Bardapure M, Thomas J, Browning AJ, Gill K and Biyani CS: Adult multilocular cystic nephroma: Report of six cases with clinical, radio-pathologic correlation and review of literature. Urol Ann 5: 13-17, 2013.

4. Edmunds W: Cystic adenoma of the kidney. Trans Pathol Soc London 43: 89-90, 1892.

5. Castillo OA, Boyle ET and Kramer SA: Multilocular cysts of kidney. A study of 29 patients and review of literature. Urology 37: 156-162, 1991.

6. Sacher P, Willi UV, Niggli F and Stallmach T: Cystic nephroma: A rare benign renal tumor. Pediatr Surg Int 13: 197-199, 1998.

7. Eble J and Bonsib SM: Extensively cystic renal neoplasms: Cystic nephroma, cystic partially differentiated nephroblastoma, multilocular cystic renal cell carcinoma and cystic hamartoma of the renal pelvis. Semin Diagn Pathol 15: 2-20, 1998.

8. Kajani N, Rosenberg BF and Bernstein J: Multilocular cystic nephroma. J Urol Pathol 1: 33-42, 1993.

9. Eble JN: Cystic nephroma and cystic partially differentiated nephroblastoma: Two entities or one? Adv Anat Pathol 1: 99-102, 1994.

10. Adsay NV, Eble JN, Srigley JR, Jones EC and Grignon DJ: Mixed epithelial stromal tumor of the kidney. Am J Surg Pathol 24: 958-970, 2000.

11. Eble J: Cystic partially differentiated nephroblastoma. In: World Health Organization Classification of Tumours Pathology and Genetics of Tumours of the Urinary System and Male Genital Organs. Eble JN, Sauter G, Epstein JI and Sesterhenn IA (eds). IARC Press, Lyon, p55, 2004.

12. Bonsib SM: Cystic nephroma. In: World Health Organization Classification of Tumours Pathology and Genetics of Tumours of the Urinary System and Male Genital Organs. Eble JN, Sauter G, Epstein JI and Sesterhenn IA (eds). IARC Press, Lyon, p76, 2004.

13. Argani P, Bruder E and Dehner L: Paediatric cystic nephroma. In: World Health Organization Classification of Tumors: Pathology and Genetics of Tumors of the Urinary System and Male Genital Organs. 4th edition. Moch H, Humphrey PA, Ulbright TM and Reuter VE (eds). IARC Press, Lyon, p52, 2016.

14. Bahubeshi A, Bal N, Rio Frio T, Hamel N, Pouchet C, Yilmaz A, Soglio DB, Williams GM, Tischkowitz M, Priest JR and Foulkes WD: Germline DICER1 mutations and familial cystic nephroma. J Med Genet 47: 863-866, 2010.

15. Caliò A, Eble JN, Grignon DJ and Delahunt B: Cystic nephroma in adults: A clinicopathologic study of 46 cases. Am J Surg Pathol 40: 1591-1600, 2016.

16. Srigley JR, Delahunt B, Eble JN, Egevad L, Epstein JI, Grignon D, Hes O, Moch H, Montironi R, Tickoo SK, et al: ISUP renal tumor panel. The international society of urological pathology (ISUP) vancouver classification of renal neoplasia. Am J Surg Pathol 37: 1469-1489, 2013.

17. Michal M, Amin MB and Delahunt B: Mixed epithelial stromal tumor family. In: World Health Organization Classification of Tumors: Pathology and Genetics of Tumors of the Urinary System and Male Genital Organs. 4th edition. Moch H, Humphrey PA, Ulbright TM and Reuter VE (eds). IARC Press, Lyon, pp70-71, 2016.

18. Boggs LK and Kimmelstiel P: Benign multilocular cystic nephroma: Report of two cases of so-called multilocular cyst of the kidney. J Urol 76: 530-541, 1956. 
19. Joshi VV and Beckwith JB: Multilocular cyst of the kidney (cystic nephroma) and cystic, partially differentiated nephroblastoma. Terminology and criteria for diagnosis. Cancer 64: 466-479, 1989

20. de Wall JG, Schroder FH and Scholtmeijer RJ: Diagnostic workup and treatment of multilocular cystic kidney. Difficulties in differentialdiagnosis. Urology 28: 73-77, 1986.

21. Posso M, Safadi D and Van Dyk OJ: Unilateral polycystic or multicystic kidney associated with focal mural renal cell carcinoma: Presentation of a case. J Urol 109: 559-563, 1973

22. Osathanondh V and Potter EL: Pathogenesis of polycystic kidneys: Type 2 due to inhibition of ampullary activity. Arch Pathol 77: 474-484, 1964

23. Raj GV, Yowell C, Madden JF, Nosnik I, Mouraviev V and Polascik TJ: Malignant cystic nephroma. Can J Urol 13: 3348-3350, 2006.

24. Silverman SG, Pedrosa I, Ellis JH, Hindman NM, Schieda N, Smith AD, Remer EM, Shinagare AB, Curci NE, Raman SS, et al: Bosniak classification of cystic renal masses, version 2019: An update proposal and needs assessment. Radiology 292: 475-488, 2019.

25. Sharma S, Nagar R, Singh K and Chrungoo RK: Cystic nephroma: An unusual renal lesion. J Urol 163: 1860, 2000.

26. Bastian PJ, Kuhlmann R, Vogel J and Bastian HP: Local recurrence of a unilateral cystic nephroma. Int J Urol 11: 329-331, 2004.

27. Cheng EY, Cohn RA, Palmer LS, Fernbach S and Firlit CF: A rare case of bilateral multilocular renal cysts. J Urol 157 1861-1862, 1997.
28. Ljungberg B, Albiges L, Abu-Ghanem Y, Bensalah K, Dabestani S, Fernández-Pello S, Giles RH, Hofmann F, Hora M, Kuczyk MA, et al: European association of urology guidelines on renal cell carcinoma: The 2019 update. Eur Urol 75: 799-810, 2019.

29. Paner GP, Stadler WM, Hansel DE, Montironi R, Lin DW and Amin MB: Updates in the eighth edition of the tumornode-metastasis staging classification for urologic cancers. Eur Urol 73: 560-569, 2018.

30. Fujita K, Ueki T and Matsushima H: An atypical multilocular cystic nephroma presenting recurrent lumbago. Nihon Hinyokika Gakkai Zasshi 84: 1883-1886, 1993 (In Japanese).

31. Egea JP, Compiano LO, Martínez F, García FG, Gutierrez AS, Galiano JL and Ros MT: Multilocular cystic nephroma. A diagnostic and therapeutic challenge. Report of two cases. Arch Esp Urol 57: 431-434, 2000 (In Spanish).

32. Kural AR, Öbek C, Özbay G and Önder AU: Multilocular cystic nephroma: An unusual localization. Urology 52: 897-899, 1998.

33. Gettman MT and Segura JW: An unusual case of multilocular cystic nephroma with prominent renal pelvis involvement treated with nephron sparing techniques. J Urol 162: 482, 1999.

(i) () () This work is licensed under a Creative Commons CY No ND Attribution-NonCommercial-NoDerivatives 4.0 International (CC BY-NC-ND 4.0) License. 